\title{
Conjugation by Mosquito Pathogenic Strains of Bacillus sphaericus
}

\author{
Margarita Correa, Allan A Yousten ${ }^{+}$
}

Microbiology Section, Biology Department, Virginia Tech, Blacksburg, Virginia 24061, U.S.A.

A mosquito pathogenic strain of Bacillus sphaericus carried out the conjugal transfer of plasmid pAMß1 to other strains of its own and two other serotypes. However, it was unable to conjugate with mosquito pathogens from three other serotypes, with B. sphaericus of other DNA homology groups or with three other species of Bacillus. Conjugation frequency was highest with a strain having an altered surface layer (S layer). Conjugal transfer of pAM $\beta 1$ was not detected in mosquito larval cadavers. B. sphaericus 2362 was unable to mobilize pUB110 for transfer to strains that had served as recipients of $p A M \beta 1$. These observations suggest that it is unlikely that genetically engineered $\mathrm{B}$. sphaericus carrying a recombinant plasmid could pass that plasmid to other bacteria.

Key words: Bacillus sphaericus - mosquito pathogen - bacterial conjugation

Mosquito pathogenic strains of Bacillus sphaericus have been assigned to DNA homology group IIA (Krych et al. 1980). Pathogenicity is caused by the production of one or more of four toxins (Charles et al. 1996, Liu et al. 1996, Thanabalu \& Porter 1996). Despite the proven effectiveness of mosquito larvicides based on $B$. sphaericus 2362, it may be useful to introduce genes for additional toxins from other bacteria such as $B$. thuringiensis or to add genes for extracellular protease to enhance manufacturing efficiency on protein substrates. These genes would initially be introduced on plasmid cloning vectors carrying antibiotic resistance genes as markers. The transfer of the antibiotic resistance genes to other bacteria by conjugation in the aquatic environment would be undesirable. It is unknown to what extent $B$. sphaericus is able to transfer genes by conjugation. Grigorova et al. (1988) demonstrated transfer of plasmids from Streptococcus agalactiae and $S$. pyogenes to B. sphaericus but did not investigate further transfer among $B$. sphaericus strains. Orzech and Burke (1984) reported that $B$. sphaericus 1593 could accept conjugative plasmid

\footnotetext{
This research was supported by cooperative research agreement CR819744-01 from the U.S. Environmental Protection Agency, Environmental Research Laboratory (Duluth, MN). Mention of commercial products or company names does not imply endorsement by the U.S. Environmental Protection Agency.

${ }^{+}$Corresponding author. Fax: +1-540-231.9307. E-mail: Yousten@vt.edu

Received 17 September 1996

Accepted 11 December 1996
}

pAMß1 from Enterococcus faecalis JH2.2 and could transfer pAMB1 to another strain of $B$. sphaericus. Whether $B$. sphaericus could transfer the plasmid to a wider range of $B$. sphaericus strains or to other bacteria was not reported. Also, it is unknown if B. sphaericus is capable of conjugation based upon plasmids it normally carries. We addressed these questions by using the broad host range plasmid $\mathrm{pAM} \beta 1$ to investigate the range of bacteria to which a known, conjugative plasmid could be transferred. To determine if the large, cryptic plasmid carried by B. sphaericus 2362 is conjugative, the mobilizable plasmid pUB110 was used as a marker to indicate if conjugation took place.

\section{MATERIALS AND METHODS}

Bacteria and mosquito larvae - E. faecalis JH2.2 [pAMß1] and B. sphaericus 2362 [pUB110] were obtained from W Burke. B. subtilis PSL1 UM4 [pLS20] and B. subtilis IG-20 UM1 were obtained from $C$ Thorne. All other B. sphaericus isolates were from the Virginia Tech Culture Collection. Recipients in all matings were rifampicin resistant. B. sphaericus 2362 [pAMB1] was constructed by filter mating $E$. faecalis JH2.2 [pAMß1] with $B$. sphaericus 2362 and selecting erythromycin-resistant $B$. sphaericus colonies on BATS agar (Yousten et al. 1985) supplemented with $10 \mu \mathrm{g} / \mathrm{ml}$ erythromycin. The strain 2362 used as recipient was not restriction-deficient. B. subtilis PSL1 UM4 [pLS20, pUB110] was constructed by protoplast transformation (Chang \& Cohen 1979) of PSL1 UM4 [pLS20] with plasmid DNA extracted from B. sphaericus 2362 [pUB110].

Conjugation - Matings in liquid were performed by a modification of the method of Battisti 
et al. (1985). Donor (B. sphaericus 2362 [pAMß1]) and recipient (B. sphaericus 2362 rif $^{\mathrm{r}}$,lys ${ }^{-}$) were grown with shaking $(160 \mathrm{rpm})$ for $5 \mathrm{hr}$ at $30^{\circ} \mathrm{C}$ in tubes of NY broth (Difco nutrient broth supplemented with $0.05 \%$ yeast extract). The same volume $(2 \mathrm{ml})$ of donor and recipient were added to $25 \mathrm{ml}$ of NY broth and shaken $(160 \mathrm{rpm})$ at $30^{\circ} \mathrm{C}$ for $20 \mathrm{hr}$. The number of donors and recipients were enumerated on NY agar containing $10 \mu \mathrm{g} / \mathrm{ml}$ erythromycin (donor) or $25 \mu \mathrm{g} / \mathrm{ml}$ rifampicin (recipient). Transcipients were enumerated on NYSM agar (Myers \& Yousten 1978) containing both antibiotics.

Conjugation on membranes was done by a modification of the method of Koehler and Thorne (1987). Donors and recipients were grown with shaking for $5 \mathrm{hr}$ at $30^{\circ} \mathrm{C}$. One $\mathrm{ml}$ each of donor and recipient were mixed and $0.1 \mathrm{ml}$ of the mixture spread onto a $45 \mathrm{~mm}$ diameter, $0.45 \mu \mathrm{m}$ membrane filter (Millipore, Bedford, MA) placed on NYSM agar. Bacteria were incubated for $20 \mathrm{hr}$ at $37^{\circ} \mathrm{C}$. Growth was washed off the membrane into $2 \mathrm{ml} \mathrm{NY}$ broth, diluted and plated. Donors, recipients, and transcipients were enumerated as described above using $25 \mu \mathrm{g} / \mathrm{ml}$ rifampicin and either $10 \mu \mathrm{g} / \mathrm{ml}$ erythromycin (pAMß1) or $5 \mu \mathrm{g} / \mathrm{ml}$ neomycin (pUB110).

Conjugation in mosquito larval cadavers was tested by feeding third instar larvae of Culex quinquefasciatus, mixtures containing equal numbers of donor and recipient spores as previously described (Correa \& Yousten 1995). The larvae were removed from the spore suspension, rinsed, and placed in clean water lacking spores. At $0 \mathrm{hr}$ (immediately upon completion of feeding), at 48 $\mathrm{hr}$ and at $72 \mathrm{hr}, 75$ larvae were removed, rinsed in sterile water, and homogenized in a sterile glass tissue grinder. At $48 \mathrm{hr}$ and at $72 \mathrm{hr}$, all the larvae removed were dead. The homogenate was divided, and part heated $\left(80^{\circ} \mathrm{C}, 12 \mathrm{~min}\right)$ and part held unheated prior to plating on NYSM agar containing erythromycin and rifampicin. Conjugation frequency in all experiments was the number of transcipients divided by the number of potential recipients.

Verification of transcipient identity and plasmid transfer - To verify that the putative transcipients were derived from the recipients, recipients were either amino acid auxotrophs (strain 2362 lys $^{-}$and 1691 his $^{-}$) or possessed different sensitivity to bacteriophages (Yousten et al. 1980) than the donors. Representative transcipients were selected and tested for these traits. Plasmid extraction and electrophoresis was done as described by Seyler et al. (1993).

\section{RESULTS}

The effect of incubation time on membranes on conjugation frequency was tested by mating $B$. sphaericus 2362 [pAMß1] with B. sphaericus 2362 lys ${ }^{-}$and plating after 3, 6, 9 and $20 \mathrm{hr}$. There was an approximate 20 -fold increase in frequency as the incubation was extended from 3 to $20 \mathrm{hr}$. The same pair of strains was used in $20 \mathrm{hr}$ filter mating to demonstrate an approximate doubling in conjugation frequency as the temperature of membrane incubation was increased from $25^{\circ} \mathrm{C}$ to $30^{\circ} \mathrm{C}$ and another doubling with an increase from $30^{\circ} \mathrm{C}$ to $37^{\circ} \mathrm{C}$ (data not shown). Subsequent filter matings were carried out for $20 \mathrm{hr}$ at $37^{\circ} \mathrm{C}$. Conjugation frequency in broth and on membranes was compared by mating $B$. sphaericus 2362 [pAMß1] with $B$. sphaericus 2362 lys $^{-}$. Conjugation frequencies in broth were much lower $\left(7.2 \times 10^{-7} \pm 1.7 \times 10^{-7}\right)$ than on membranes $\left(1.9 \times 10^{-4} \pm 1.1 \times 10^{-4}\right)$.

B. sphaericus 2362 and other mosquito pathogens belong to DNA homology group IIA whereas the type strain of the species, ATCC 14577, is a nonpathogen and belongs to homology group I. Additional nonpathogens, all presently referred to as B. sphaericus, are found in four other homology groups. The pathogens of group IIA have been subdivided by serotyping. To determine the ability of mosquito pathogenic strain 2362 to transfer pAMß1 to other bacteria, filter matings were performed and the results are reported in Table. In addition to being able to transfer the plasmid to 2362 at a mean frequency of $1.9 \times 10^{-4}, 2362$ [pAMß1] successfully transferred pAM $\beta 1$ to strains 1593 and 1691 of the same serotype (5a5b) as the donor and to strains 2297 and 31-2 of serotypes 25 and $9 \mathrm{a} 9 \mathrm{c}$ respectively. However, no transfer was detected to mosquito pathogens IAB460 (serotype 6), SSII-1 (serotype 2), or Kellen Q (serotype 1). Also, pAMß1 was not transferred to nonpathogenic B. sphaericus strain ATCC 14577 (homology group I), to NRS 1199 (homology group $\mathrm{V}$ ) or to a B. sphaericus (homology group V) isolated from mud in a local mosquito breeding site. To test for the possibility of interspecies conjugation, $B$. subtilis IG-20, a restrictionless variant, as well as $B$. mycoides and $B$. thuringiensis var. israelensis were used as recipients. No transfer of pAMß1 was detected.

The highest conjugation frequency detected in this series of experiments was found with $B$. sphaericus $1593-5-1$ as recipient. The mean frequency was about 15 -fold higher than with 2362 as recipient and about 7-fold higher than with the parental 1593 as recipient. Strain 1593-5-1 is the same homology group and serotype as the donor, 2362 [pAMß1], but differs by possessing a sur- 
TABLE

Conjugation frequencies between Bacillus sphaericus 2362 [pAMB1] and other strains of B. sphaericus $^{a}$

\begin{tabular}{lll}
\hline $\begin{array}{l}\text { Recipient } \\
\text { strain }\end{array}$ & Serotype & $\begin{array}{l}\text { Conjugation frequency } \\
(\text { mean } \pm \text { SD) }\end{array}$ \\
\hline 2362 & 5a5b & $1.90 \times 10^{-4} \pm 1.13 \times 10^{-4}$ \\
1593 & $5 \mathrm{a} 5 \mathrm{~b}$ & $4.03 \times 10^{-4} \pm 3.07 \times 10^{-4}$ \\
$1593-5-1$ & $5 \mathrm{a} 5 \mathrm{~b}$ & $2.93 \times 10^{-3} \pm 2.56 \times 10^{-4}$ \\
1691 & $5 \mathrm{a} 5 \mathrm{~b}$ & $1.80 \times 10^{-5} \pm 7.07 \times 10^{-6}$ \\
2297 & 25 & $2.20 \times 10^{-4} \pm 1.41 \times 10^{-4}$ \\
$31-2$ & $9 \mathrm{a} 9 \mathrm{c}$ & $8.85 \times 10^{-5} \pm 3.04 \times 10^{-5}$ \\
\hline
\end{tabular}

$a$ : donor strain was neomycin resistant and all recipient strains were rifampicin resistant. Transcipients were selected on medium containing both antibiotics.

face protein layer, S layer, of lower molecular weight than the parent strain 1593 (Lewis \& Yousten 1988). The mutant was isolated based on its resistance to phage 4, a lytic phage for both 2362 and the parental strain 1593. The phage resistance was used as positive identification of the transcipients.

Evidence against transformation or transduction being involved in pAMß1 transfer was provided by carrying out the mating on a membrane incubated on medium containing $100 \mu \mathrm{g} / \mathrm{ml}$ DNase and by substituting filter sterilized culture supernatant from the donor for the donor bacteria themselves. DNase did not affect the frequency of recovering erythromycin resistant colonies and no erythromycin resistant bacteria were found when culture supernatant was incubated in place of the donor bacteria.

Several large, self-transmissible, usually cryptic plasmids detected in $B$. thuringiensis and $B$. subtilis can mobilize the transfer of smaller plasmids (Battisti et al. 1985, Koehler \& Thorne 1987, Reddy et al. 1987). It was unknown if the large, cryptic plasmid residing in $B$. sphaericus 2362 was conjugative and if it might be capable of mobilizing plasmids. This was tested using strain 2362 carrying the large, cryptic plasmid as well as the $4.5 \mathrm{~kb}$ pUB110.

The pUB110 present in the strain 2362 that was to be used as donor was proven to be mobilizable by transferring the plasmid to $B$. subtilis PSL1 UM4 [pLS20] by protoplast transformation. pLS20 had been shown to promote the transfer of pUB110 (Battisti et al. 1985). B. subtilis PSL1 UM4 [pLS20, pUB110] was filter mated with $B$. subtilis IG-20 UM1 and transcipients selected on a medium containing $10 \mu \mathrm{g} / \mathrm{ml}$ rifampicin and $5 \mu \mathrm{g} / \mathrm{ml}$ neomycin. Conjugation frequency obtained in this mating was equal to that reported by Koehler and
Thorne (1987) who used the same B. subtilis strains. This demonstrated that the pUB110 used in experiments with B. sphaericus was capable of being mobilized.

B. sphaericus 2362 [pUB110] was filter mated with B. sphaericus 2362, 1691, 2297 and 31-2, four strains that had been shown to be effective recipients for pAMß1. It was also mated with strains Kellen Q and 1883 (serotype 2). In none of these experiments were transcipients recovered.

If $B$. sphaericus was able to transfer recombinant plasmids by conjugation following its dispersal as a larvicide in the aquatic environment, the most likely site for this to take place would be in the larval cadaver. In this site the spores of $B$. sphaericus are known to germinate and grow vegetatively in the presence of large numbers of bacteria indigenous to the larvae (Correa \& Yousten 1995). To test the suitability of the larval cadaver as a site for conjugation, spores of strain 2362 [pAMß1] were fed with spores of either $2362 \mathrm{lys}^{-}$ or 1593-5-1 to third instar mosquito larvae. Larvae accumulated between $10^{5}$ and $10^{6}$ spores of each strain per larva. In two trials with each recipient strain, no transcipients were recovered at either $48 \mathrm{hr}$ or $72 \mathrm{hr}$ after feeding, although these same combinations of bacteria had been shown to conjugate when filter mated. To test whether soluble substances in the larval cadaver might interfere with conjugation, larval homogenate was mixed with cells of 2362 [pAMß1] and 1593-5-1 when they were placed on filter membranes for mating. There was no decrease in conjugation frequency in the presence of homogenate.

\section{DISCUSSION}

The broad host range, conjugative plasmid pAMB1 was used to determine favorable conditions for plasmid donation by B. sphaericus 2362 . With the same strain as recipient, conjugation frequency increased both with increase in temperature and time of incubation. The frequency was much higher when mating was done on a membrane surface than when done in broth, a common observation among gram positive bacteria.

Transfer of pAMß1 was successful when strains of the same serotype ( $5 \mathrm{a} 5 \mathrm{~b}$ ) as the 2362 donor were used as recipients. pAMB1 was also transferred to two other pathogens, strains 2297 and 31-2, of different serotypes. However, not all strains of DNA homology group IIA (mosquito pathogens) functioned as recipients. Strains IAB460, SSII-1, and $\mathrm{Q}$ yielded no transcipients. Also, strains outside homology group IIA as well as three other species of Bacillus did not yield transcipients. Successful recipients of serotype $5 \mathrm{a} 5 \mathrm{~b}$ are known to have restriction endonucleases, but these are likely to have 
DNA modified in the same way as the donor (2362) of that serotype. Strains 2297 and 31-2 of different serotypes than the donor lack restriction endonuclease activity and this may explain their success as recipients. Kellen $\mathrm{K}$ and SSII- 1 have restriction endonuclease of different specificity than 2362 and this may explain their failure as recipients (Zahner \& Priest, pers. comm.). Also, $B$. sphaericus possesses a surface protein layer ( $\mathrm{S}$ layer) that is presumably the point of contact between cells at the initiation of conjugation. The protein of this layer is known to differ immunologically and in peptide maps between serotypes. It also differs in arrangement of subunits between homology groups (Lewis et al. 1987). It is possible that differences in S-layer protein create physical barriers that prevent plasmid transfer. The observation that the conjugation frequency was higher with a mutant strain (1593-5-1) having a modified S-layer protein than with the parent strain, suggests that the S layer may be involved in conjugation in this species.

The existence of cryptic, conjugal plasmids in B. thuringiensis was demonstrated by detecting the mobilization of pUB110 and pBC16 (Battisti et al. 1985, Reddy et al. 1987). However, no transfer of pUB110 was detected from B. sphaericus 2362 to strains that had been shown to be recipients for transfer of pAMß1. This indicates that the large, cryptic plasmid of $B$. sphaericus 2362 is not capable of mobilizing smaller plasmids.

Jarrett and Stephenson (1990) demonstrated plasmid transfer between strains of $B$. thuringiensis in cadavers of lepidopteran larvae killed by the toxins of that bacterium. No transcipients were recovered from mosquito larvae killed by the mixture of B. sphaericus spores fed to them although the same strains were capable of transferring pAMB1 on membranes. It is possible that the conditions in the larval cadavers are not suitable for conjugation or that the failure to detect transcipients is related to the frequency of conjugation and the number of bacteria available in the cadavers. If the frequency of conjugation was similar to that found on membranes (about $10^{-3}$ to $10^{-4}$ for the recipients tested in larvae), a few transcipients should have been recovered from among the recipient cells present in each cadaver. However, conjugation frequency was much lower in broth than on membranes, and the conditions in the decomposing cadaver may have resembled broth more than membrane. A lower conjugation frequency similar to that in broth would have produced too few transcipients to detect unless several hundred or thousand larval cadavers had been examined. The number of $B$. thuringiensis cells in the lepidopteran larvae used by Jarrett and Stephenson (1990) was higher (about $10^{6}$ to $10^{7}$ per larva) than the number present in smaller mosquito larvae. Different conditions in the lepidopteran cadaver and a higher number of bacteria may have been responsible for conjugation in that site. If conjugation occurred in mosquito larval cadavers, it was a rare event below the level of our detection sensitivity in these experiments.

The failure of B. sphaericus 2362 to mobilize transfer of pUB110 and the apparent low (undetectable) conjugation frequency of a known conjugative plasmid in larval cadavers, indicates that it is unlikely that genetically engineered $B$. sphaericus would pass recombinant plasmids to other bacteria in the larval cadaver.

\section{ACKNOWLEDGEMENT}

To Viviane Zahner and Fergus Priest for sharing unpublished data on restriction endonuclease activity.

\section{REFERENCES}

Battisti L, Green B, Thorne C 1985. Mating system for transfer of plasmids among Bacillus anthracis, Bacillus cereus, and Bacillus thuringiensis. J Bacteriol 162: 543-550.

Chang S, Cohen S 1979. High frequency transformation of Bacillus subtilis protoplasts by plasmid DNA. Mol Gen Genet 168: 111-115.

Charles J-F, Nielsen-LeRoux C, Delecluse A 1996. Bacillus sphaericus toxins: Molecular biology and mode of action. Annu Rev Entomol 41: 451-472.

Correa M, Yousten A 1995. Bacillus sphaericus spore germination and recycling in mosquito larval cadavers. J Invert Pathol 66: 67-81.

Grigorova R, Michailova L, Miteva V, Peneva N, Ganova L, Takova TS 1988. Conjugal transfer of streptococcal plasmids to strains of Bacillus sphaericus. FEMS Microbiol Lett 49: 289-294.

Jarrett P, Stephenson M 1990. Plasmid transfer between strains of Bacillus thuringiensis infecting Galleria mellonella and Spodoptera littoralis. Appl Environ Microbiol 56: 1608-1614.

Koehler T, Thorne C 1987. Bacillus subtilis (natto) plasmid pLS20 mediates interspecies plasmid transfer. J Bacteriol 169: 5271-5278.

Krych V, Johnson J, Yousten A 1980. Deoxyribonucleic acid homologies among strains of Bacillus sphaericus. Int J Syst Bacteriol 30: 476-484.

Lewis L, Yousten A 1988. Bacteriophage attachment to the S-layer protein of the mosquito-pathogenic strains of Bacillus sphaericus. Curr Microbiol 17: 55-60.

Lewis L, Yousten A, Murray RGE 1987. Characterization of the surface protein layers of the mosquitopathogenic strains of Bacillus sphaericus. J Bacteriol 69: 72-79.

Liu J-W, Porter A, Wee BY, Thanabalu T 1996. New gene from nine Bacillus sphaericus strains encoding highly conserved 35.8-kilodalton mosquitocidal 
toxins. Appl Environ Microbiol 62: 2174-2176.

Myers P, Yousten A 1978. Toxic activity of Bacillus sphaericus SSII-1 for mosquito larvae. Infect Immun 19: 1047-1053.

Orzech K, Burke W 1984. Conjugal transfer of pAMß1 in Bacillus sphaericus 1593. FEMS Microbiol Lett 25: 91-95.

Reddy A, Battisti L, Thorne C 1987. Identification of self-transmissible plasmids in four Bacillus thuringiensis subspecies. J Bacteriol 169: 52635270.

Seyler R, Yousten A, Thal T, Burke W 1993. Stability of pUB110 and pUB110-derived plasmids in Bacil- lus sphaericus 2362. Appl Microbiol Biotechnol 39: 520-525.

Thanabalu T, Porter A 1996. A Bacillus sphaericus gene encoding a novel type of mosquitocidal toxin of 31.8 kDa. Gene 170: 85-89.

Yousten A, deBarjac H, Hedrick J, Cosmao Dumanoir V, Myers P 1980. Comparison between bacteriophage typing and serotyping for the differentiation of Bacillus sphaericus. Ann Microbiol (Inst Pasteur) 131B: 297-308.

Yousten A, Fretz S, Jelley S 1985. Selective medium for mosquito-pathogenic strains of Bacillus sphaericus. Appl Environ Microbiol 49: 1532-1533. 
